\title{
Produtividade de almeirão orgânico produzido com substratos alternativos
}

\section{Productivity of organic Cichorium intybus produced with alternative substrates}

\author{
Thays Lemos Uchôa ${ }^{1 *}$, Waldiane Araújo de Almeida ${ }^{2}$, Sebastião Elviro de Araújo Neto ${ }^{3}$, Luís Gustavo de Souza e Souza ${ }^{4}$, \\ Regina Lúcia Félix Ferreira ${ }^{5}$, Nilciléia Mendes da Silva
}

\begin{abstract}
Resumo: O objetivo deste trabalho foi avaliar substratos alternativos na qualidade de mudas e produtividade do almeirão em cultivo orgânico. O experimento foi conduzido em duas fases: em viveiro e em campo, em junho de 2016.0 campo experimental está localizado no Sítio Ecológico Seridó, em Rio Branco, Acre. O delineamento utilizado foi em blocos casualizados com cinco tratamentos e quatro repetições. Os tratamentos foram constituídos pelo substrato comercial Golden ${ }^{\circledR}$ utilizado como controle e por mais quatro substratos alternativos. Os substratos alternativos foram compostos por: terra (30\%), composto orgânico (30\%); condicionador de solo (30\%), carvão $(10 \%)$, termofosfato natural $\left(1,5 \mathrm{~kg} \mathrm{~m}^{-3}\right)$, calcário dolomítico $\left(1,0 \mathrm{~kg} \mathrm{~m}^{-3}\right)$ e sulfato de potássio $\left(1,0 \mathrm{~kg} \mathrm{~m}^{-3}\right)$, o que os diferenciaram foi a substituição do condicionador: casca de arroz carbonizada; fibra de coco; fibra do caule da palmeira ouricurí (Attalea phalerata) ou caule decomposto de sumaúma (Ceiba pentandra). A cultivar utilizada foi almeirão pão de açúcar. Aos 22 dias após a semeadura as mudas foram avaliadas para a obtenção do índice de qualidade e aos 60 dias após o transplantio a campo avaliou-se a massa fresca total, comercial, seca total, comercial e a produtividade total e comercial. Os substratos contendo sumaúma e fibra de coco tiveram melhor desempenho para massa seca da raiz e índice de qualidade de Dickson na fase de muda, massa fresca total, massa seca total e comercial e produtividade total à campo.
\end{abstract}

Palavras-chave: Cichorium intybus; Cultivo orgânico; Produção de mudas.

\begin{abstract}
The objective of this work was to evaluate alternative substrates in the quality of seedlings and in the productivity of chicory in organic cultivation. The experiment conducted in two phases: plant nursery and field, in June 2016. The experimental field is located at Seridó Ecological farm, in Rio Branco, Acre. The experimental design was a randomized block with five treatments and four replications. The treatments constituted by the Golden commercial substrate used as control and by four other alternative substrates: soil (30\%), organic compound (30\%); Soil conditioner (30\%), coal (10\%), natural thermophosphate $\left(1.5 \mathrm{~kg} \mathrm{~m}^{-3}\right)$, dolomitic limestone $\left(1.0 \mathrm{~kg} \mathrm{~m}^{-3}\right)$ and potassium sulphate $\left(1.0 \mathrm{~kg} \mathrm{~m}^{-3}\right)$. What differentiated them was the substitution of the conditioner: Carbonized rice husk; Coconut fiber; Fiber of the stem of ouricurí palm (Attalea phalerata) or Cork decomposed of kapok (Ceiba pentandra). The cultivar used was Sugar loaf. At 22 days after sowing, the seedlings evaluated to obtain the quality index and at 60 days after transplanting to the field the total fresh mass, commercial, total dry, commercial and total and commercial productivity were evaluated. The substrates containing kapok and coconut fiber had better performance for root dry mass and Dickson quality index in the seedlings phase, total fresh mass, total and commercial dry mass and total field productivity.
\end{abstract}

Key words: Cichorium intybus; Organic farming; Seedling production.

\footnotetext{
*Autor para correspondência

Recebido para publicação em 17/08/2017; aprovado em 30/03/2018

${ }^{1}$ Engenheira Agrônoma Mestre em Produção Vegetal, Universidade Federal do Acre, Rio Branco, Acre; (068) 999671592, thays_uchoa@yahoo.com.br

${ }^{2}$ Engenheira Agrônoma Mestre em Produção Vegetal, Universidade Federal do Acre, Rio Branco, Acre, waldianearaujo@hotmail.com

${ }^{3}$ Engenheiro Agrônomo Doutorado em Fitotecnia. Professor Associado II da Universidade Federal do Acre, Rio Branco, Acre, selviro2000@yahoo.com.br

${ }^{4}$ Engenheiro Agrônomo Universidade Federal do Acre, Rio Branco, Acre, gustavo_souza_fj@hotmail.com

${ }^{5}$ Engenheira Agrônoma Doutorado em Fitotecnia. Professora Adjunto III da Universidade Federal do Acre, Rio Branco, Acre, reginalff@yahoo.com.br

${ }^{6}$ Engenheira Agrônoma Universidade Federal do Acre, Rio Branco, Acre, nilcileia-ac@ hotmail.com
} 


\section{INTRODUÇÃO}

O almeirão (Cichorium intybus L.) é originário da Europa mediterrânea, pertencente à família Asteraceae. Planta herbácea com ciclo anual, folhosa, seu consumo é principalmente in natura, com uso em saladas e apresenta pronunciado sabor amargo (FILGUEIRA, 2013). É uma hortaliça com boas propriedades nutricionais, aminoácidos, cálcio, fibras, ferro, fósforo, potássio, vitaminas A, B1, B2, B5 e C, entretanto, para conservação dessas características seu consumo deve ser feito sem processamento (LUENGO et al., 2000). Além disso, possui propriedades antibacterianas, anti-inflamatórias, digestivas, diuréticas (SAEED et al., 2015).

A qualidade das mudas é a fase fundamental para o ciclo da cultura, influenciando até o desempenho final da planta (SIMÕES et al., 2015). As características nutricionais e a produção são utilizadas como medidas de padrão de qualidade das mudas, existindo relação direta entre vigor das mudas sadias a serem transplantadas para o campo (COSTA et al., 2013). Portanto, mudas de qualidade incrementam a produtividade, enquanto as mal formadas, segundo Guimarães et al. (2002) comprometem o desenvolvimento da cultura, ampliam seu ciclo e ocasionando perdas na produção.

$\mathrm{Na}$ fase de produção de mudas, diversos fatores influenciam seu desenvolvimento, como a semente, manejo, fertilidade, volume do recipiente e principalmente o substrato. A composição dos substratos é de grande valia, pois a germinação está diretamente ligada a características química, física e biológica, para crescimento adequado, além de exercer influência na disposição do sistema radicular (MOLLITOR et al., 2004; ZIETEMANN; ROBERTO, 2007).

Os substratos podem ser formados pela combinação adequada de diferentes tipos de materiais ou pela utilização de apenas um que possua as caraterísticas desejáveis, como disponibilidade de aquisição, simples manuseio e transporte e ainda suportar condições bióticas adversas. Materiais orgânicos estão sendo utilizados na composição de substratos para determinar os mais apropriados para o desenvolvimento de cada espécie, visando fornecimento adequado de fertilidade, capacidade de troca catiônica, aeração, drenagem, retenção e troca de água, que junto as influenciam a qualidade das mudas (ARAÚJO NETO et al., 2009; DELARMELINA et al., 2013; KNAPIK et al., 2005; TRAZZI et al., 2013).

Os componentes dos substratos alternativos são sustentáveis do ponto de vista socioeconômico e ambiental, no entanto, dependem da disponibilidade de material de qualidade para sua composição e pode ser variado conforme a característica da região (CASTOLDI et al., 2014; PEREIRA et al., 2012).
Não existe um substrato ideal para todas as espécies e condições, apresentando a necessidade de estudos de preferência de baixo custo e fácil aquisição. Portanto, objetivou-se com esse trabalho avaliar substratos alternativos na qualidade de mudas e produtividade do almeirão em cultivo orgânico.

\section{MATERIAL E MÉTODOS}

O experimento foi realizado no Sítio Ecológico Seridó, localizado na Rodovia AC 10, km 04, Ramal José Rui Lino, em Rio Branco, AC, com coordenadas de 0953'16" S e $67^{\circ} 49^{\prime} 11^{\prime \prime} \mathrm{W}$, e altitude de $170 \mathrm{~m}$. O clima da região é do tipo Am, quente e úmido, segundo a classificação de Köppen, com temperaturas médias anuais em torno de $27,31{ }^{\circ} \mathrm{C}$, umidade relativa do ar de $83,08 \%$ e a precipitação média mensal 142,53 mm (INMET, 2016).

O trabalho foi conduzido em duas fases: (1) avaliação das mudas produzidas nos substratos em viveiro e (2) avaliação da produção em campo utilizando as mudas com diferentes padrões de qualidade.

Os atributos químicos presentes no solo onde foi instalado $\mathrm{O}$ experimento apresentavam os seguintes conteúdos: $\mathrm{pH}=6,4 ;$ M.O. $=30,0 \mathrm{~g} \mathrm{dm}^{-3} ; \mathrm{P}=15 \mathrm{mg} \mathrm{dm}^{-3} ; \mathrm{K}$ $=1,5 \mathrm{mmol}_{\mathrm{c}} \mathrm{dm}^{-3} ; \mathrm{Ca}=62,0 \mathrm{mmol}_{\mathrm{c}} \mathrm{dm}^{-3} ; \mathrm{Mg}=19 \mathrm{mmol}_{\mathrm{c}}$ $\mathrm{dm}^{-3} ; \mathrm{Al}=1,0 \mathrm{mmol}_{\mathrm{c}} \mathrm{dm}^{-3} ; \mathrm{H}+\mathrm{Al}=20,0 \mathrm{mmol}_{\mathrm{c}} \mathrm{dm}^{-3} ; \mathrm{SB}=$ $82,5 \mathrm{mmol}_{\mathrm{c}} \mathrm{dm}^{-3} ; \mathrm{CTC}=102,5 \mathrm{mmol}_{\mathrm{c}} \mathrm{dm}^{-3} ; \mathrm{V}=80,4 \%$.

$\mathrm{O}$ delineamento experimental foi em blocos casualizados com cinco tratamentos e quatro repetições. A unidade experimental no viveiro foi formada por 10 mudas e no campo 16 plantas em parcelas medindo $1,2 \mathrm{~m} \mathrm{x} 1,2 \mathrm{~m}$, plantadas em quatro linhas no espaçamento de $30 \mathrm{~cm}$ x 30 $\mathrm{cm}$, sendo a área útil de seis plantas das duas linhas centrais eliminando a bordadura.

Os tratamentos foram constituídos pelo substrato comercial utilizado como tratamento controle e por mais quatro substratos alternativos. Os substratos alternativos foram compostos por: terra (30\%), composto orgânico (30\%); condicionador de solo (30\%), carvão $(10 \%)$, termofosfato natural $\left(1,5 \mathrm{~kg} \mathrm{~m}^{-3}\right)$, calcário dolomítico $\left(1,0 \mathrm{~kg} \mathrm{~m}^{-3}\right)$ e sulfato de potássio $\left(1,0 \mathrm{~kg} \mathrm{~m}^{-3}\right)$, o que os diferenciaram foi a substituição do condicionador: casca de arroz carbonizada; fibra de coco; fibra do caule da palmeira ouricurí (Attalea phalerata) e caule decomposto de sumaúma (Ceiba pentandra). Observa-se a composição química (Tabela 1) e física dos substratos (Tabela 2).

A casca de arroz foi carbonizada, já a fibra de coco, casca de ouricurí e sumaúma foram triturados e peneirados para melhor homogeneização no substrato. A terra utilizada na composição do substrato foi retirada da profundidade de 0 $0,05 \mathrm{~m}$ do solo.

Tabela 1. Composição químicos dos substratos alternativos. Rio Branco, Acre

\begin{tabular}{ccccccccccccc}
\hline \multirow{2}{*}{ Substratos } & $\mathrm{pH}$ & $\mathrm{P}$ & $\mathrm{K}$ & $\mathrm{Ca}$ & $\mathrm{Mg}$ & $\mathrm{S}$ & $\mathrm{B}$ & $\mathrm{Cu}$ & $\mathrm{Fe}$ & $\mathrm{Mn}$ & $\mathrm{Na}$ \\
\cline { 2 - 12 } & & & & & & & $\left(\mathrm{mg} \mathrm{L}^{-1}\right)$ & & & \\
\hline CAC & 7,5 & 6,56 & 194,0 & 108,0 & 25,3 & 119,0 & 0,23 & 0,04 & 3,76 & 0,58 & \\
Fibra de coco & 7,4 & 5,0 & 274,0 & 59,1 & 19,4 & 108,0 & 0,15 & 0,04 & 4,76 & 0,61 & 31,0 \\
Sumaúma & 8,1 & 2,65 & 148,0 & 130,0 & 26,8 & 92,2 & 0,07 & 0,03 & 3,61 & 0,27 & 19,0 \\
Ouricurí $^{\circledR}$ & 6,5 & 6,66 & 176,0 & 153,0 & 34,2 & 129,0 & 0,29 & 0,04 & 2,00 & 0,94 & 24,0 \\
Golden $^{\circledR}$ & 5,3 & 0,4 & 84,0 & 141,0 & 76,30 & 183,0 & 0,61 & 0,01 & 0,31 & 0,13 & 14,4 \\
\hline
\end{tabular}

Casca de arroz carbonizada (CAC) + mistura (30\% terra, 30\% composto, $10 \%$ pó de carvão vegetal, $1,0 \mathrm{~kg} / \mathrm{m}^{3}$ de calcário dolomítico e $1,5 \mathrm{~kg} / \mathrm{m}^{3}$ de termofosfato natural); fibra de coco + mistura; sumaúma + mistura; ouricurí + mistura; Golden ${ }^{(\mathrm{r})}$. 
Tabela 2. Composição física dos substratos alternativos. Rio Branco, Acre.

\begin{tabular}{|c|c|c|c|c|c|c|c|c|}
\hline \multirow{2}{*}{ Substratos } & DA & DP & EP & PS & C.R.A. & \multirow{2}{*}{$\frac{\text { C.T.C. }}{\left(\mathrm{mmol}_{\mathrm{C}} \mathrm{kg}^{-1}\right)}$} & \multirow{2}{*}{$\begin{array}{c}\text { C.E. } \\
\left(\text { mili Scm }^{-1}\right) \\
\end{array}$} & \multirow{2}{*}{$\begin{array}{c}\text { M.O. } \\
\text { g } 100 g^{-1}\end{array}$} \\
\hline & \multicolumn{2}{|c|}{-----( $\left(\mathrm{kg} \mathrm{m}^{-3}\right)------$} & \multicolumn{3}{|c|}{----------(\%)---------- } & & & \\
\hline CAC & 720,6 & 2423,1 & 75,6 & 24,4 & 90,70 & 102,5 & 0,604 & 13,19 \\
\hline Fibra de coco & 589,9 & 2298,6 & 78,9 & 21,1 & 91,72 & 95,0 & 0,614 & 21,54 \\
\hline Sumaúma & 742,0 & 2380,3 & 76,9 & 23,1 & 106,60 & 160,0 & 0,453 & 15,90 \\
\hline Ouricurí & 779,3 & 2373,7 & 75,9 & 24,1 & 102,30 & 107,5 & 0,457 & 16,40 \\
\hline Golden $^{\circledR}$ & 454,0 & 1989,1 & 88,2 & 11,8 & 219,34 & 347,5 & 0,713 & 46,82 \\
\hline
\end{tabular}

$\mathrm{DA}=$ densidade aparente (base seca); $\mathrm{DP}=$ densidade de partículas; $\mathrm{EP}=$ espaço poroso; $\mathrm{PS}=$ partículas solidas; $\mathrm{C} . \mathrm{R}$.A.= capacidade de retenção de água;

C.T.C. $=$ capacidade de troca de cátions; C.E.= condutividade elétrica; M.O.= matéria orgânica. Casca de arroz carbonizada $($ CAC $)$

A semeadura foi realizada no mês de junho de 2016, em bandejas de poliestireno de 128 células, preenchidas com os substratos, utilizando três sementes por célula, o desbaste foi realizado aos oito dias, deixando-se uma plântula por célula. As bandejas permaneceram em viveiro coberto com polietileno transparente de 100 micras e as laterais protegidas por tela de antiafídica.

Aos 22 dias após a semeadura, avaliou-se: altura da muda $(\mathrm{H})$, com auxílio de régua graduada em centímetros; diâmetro do colo (DC) aferiu-se com paquímetro (mm); massa seca da parte aérea (MSPA); massa seca da raiz (MSR); massa seca total (MST) e índice de qualidade do desenvolvimento da muda (IQD). A limpeza da raiz foi realizada com lavagem em água, retirando-se o substrato aderido. Posteriormente, foi separada da parte aérea e colocadas em sacos de papel kraft identificados e posteriormente encaminhados para estufa com circulação forçada de ar a $65^{\circ} \mathrm{C}$, até obterem massa constante aferida em balança analítica de precisão.

Para determinar o IQD foi utilizada a metodologia de Dickson et al. (1960) através das seguintes variáveis: massa seca total $(\mathrm{g})$, altura $(\mathrm{cm})$, diâmetro do colo $(\mathrm{mm})$, massa seca da parte aérea e das raízes (g), conforme a equação 1 .

$$
\mathrm{IQD}=\mathrm{MST} /\left[\left(\frac{\mathrm{H}}{\mathrm{DC}}\right)+\left(\frac{\mathrm{MSPA}}{\mathrm{MSR}}\right)\right]
$$

O transplantio das mudas para o campo foi realizado aos 22 dias após a semeadura, em ambiente protegido com polietileno transparente de $100 \mu \mathrm{m}$ e as laterais abertas. O preparo do solo consistiu de capina da vegetação espontânea e construção dos canteiros com enxada à $0,20 \mathrm{~m}$ de altura. $\mathrm{O}$ solo foi revolvido e incorporado $15 \mathrm{t} \mathrm{ha}^{-1}$ de composto orgânico produzido com capim Brachiaria (base seca) até $0,10 \mathrm{~m}$ de profundidade.

A irrigação utilizada foi por microaspersão, aplicando-se lâmina d'água próximo a capacidade de campo, durante o ciclo da cultura. Não houve controle de pragas e doenças, apenas das plantas espontâneas, realizando a limpeza com auxílio de enxada, para diminuir a competição com a cultura principal.

A colheita foi realizada de forma manual 60 dias após a semeadura. As variáveis avaliadas na fase de campo foram: massa fresca comercial (MFC) e total (MST), massa seca comercial (MSC) e total (MST), produtividade total (PRODT) e comercial (PRODC).

Para determinar a massa total da planta considerou-se todas as folhas e para obter a massa comercial foi realizada a eliminação das folhas senescentes e doentes. Foram pesadas as seis plantas da parcela. As plantas foram acondicionadas em sacos de papel kraft e encaminhadas para estufa com circulação forçado de ar a $65{ }^{\circ} \mathrm{C}$, até atingir massa constante.

Para análise estatística dos dados, foi efetuada a verificação da presença de outliers pelo teste de Grubbs, a normalidade dos resíduos pelo teste de Shapiro e Wilk e a homogeneidade de variância pelo teste de Bartlett. As médias foram comparadas pelo teste de Tukey, ao nível de 5\% de probabilidade. Para as variáveis na fase de muda, massa seca total, da parte aérea, raiz e o índice de qualidade de muda e na fase de campo massa fresca total, massa seca comercial e produtividade total que não atendeu ao pressuposto efetuou-se a transformação dos dados para $\sqrt{5}, \sqrt{6}, \sqrt{5}, \sqrt{x}, \sqrt{x}, \sqrt{x}, \sqrt{6}$, respectivamente.

\section{RESULTADOS E DISCUSSÃO}

Houve diferença significativa entre os substratos para todas as características avaliadas (Tabela 3). Dentre os substratos alternativos, o que continha sumaúma como condicionador foi o que proporcionou maior massa seca da parte aérea, raiz, total e índice de qualidade de muda. Quando se utilizou a fibra de coco, obteve-se melhor desempenho da massa seca da raiz e qualidade de muda (Tabela 3 ).

Os substratos alternativos avaliados, apresentaram baixas concentrações dos nutrientes $\mathrm{P}$ e $\mathrm{Mg}$ não estando dentro da faixa ideal (Tabela 1), que devem variar entre: $\mathrm{K}$ : 110 a $179 \mathrm{mg} \mathrm{L}^{-1}$; Ca: 140 a $219 \mathrm{mg} \mathrm{L}^{-1}$; P: 8 a $13 \mathrm{mg} \mathrm{L}^{-1}$; Mg: 60 a $99 \mathrm{mg} \mathrm{L}^{-1}$ e N: 80 a $139 \mathrm{mg} \mathrm{L}^{-1}$ (PLANK, 1989). Entretanto, observa-se que mesmo não havendo a quantidade ideal desses nutrientes no substrato contendo sumaúma e a fibra de coco, houve superioridade na qualidade da muda (IQD) como pode ser observado na (Tabela 3). Logo, as raízes são indicativos da disponibilidade e deficiência de nutrientes no substrato, pois as plantas acumulam fotoassimilados no sistema radicular para auxiliar no seu crescimento (SILVA; DELATORRE, 2009).

A disponibilidade de nutrientes dos substratos orgânicos não depende apenas da composição do $\mathrm{pH}$, mas também da capacidade de adsorção, da estabilidade biológica e da presença de compostos orgânicos dissolvidos (CABALLERO et al., 2007). O fósforo, está ligado na função estrutural, transferência, armazenamento de energia e nos processos metabólicos da planta como a síntese de proteínas e ácido nucléico. $\mathrm{O}$ magnésio influencia no desenvolvimento vegetativo e quando os seus teores são baixos limita a absorção pela planta e causa a clorose, iniciando nas nervuras das folhas mais velhas (TAIZ; ZEIGER, 2013). 
Tabela 3. Massa seca da parte aérea (MSPA), massa seca de raiz (MSR), massa seca total (MST), índice de qualidade de mudas (IDQ) de almeirão cv. pão de açúcar, produzidos em diferentes substratos, Rio Branco, Acre.

\begin{tabular}{|c|c|c|c|c|}
\hline Substratos & MSPA & MSR & MST & IDQ \\
\hline $\mathrm{CAC}$ & $0.943 \mathrm{bc}$ & $166 \mathrm{~b}$ & $0988 \mathrm{bc}$ & $0180 \mathrm{bc}$ \\
\hline Fibra de coco & $0,963 \mathrm{bc}$ & $1,200 \mathrm{a}$ & $0,992 \mathrm{bc}$ & $0,231 \mathrm{a}$ \\
\hline Sumaúma & $1,016 \mathrm{a}$ & $1,192 \mathrm{a}$ & $1,003 \mathrm{a}$ & $0,233 \mathrm{a}$ \\
\hline Ouricurí & $0,969 \mathrm{~b}$ & $1,116 \mathrm{c}$ & $0,993 \mathrm{~b}$ & $0,180 \mathrm{bc}$ \\
\hline Golden & $0,924 \mathrm{c}$ & $1,080 \mathrm{~d}$ & $0,984 \mathrm{c}$ & $0,148 \mathrm{c}$ \\
\hline $\mathrm{CV}(\%)$ & 2,08 & 0,94 & 0,41 & 11,64 \\
\hline
\end{tabular}

Médias seguidas de mesma letra não diferem $(\mathrm{p}>0,05)$ entre si pelo teste de Tukey. Casca de arroz carbonizada (CAC)

Das propriedades físicas dos substratos alternativos estudados, destacam-se a maior densidade aparente e de partículas, estando associado a menor aeração e armazenamento de água (Tabela 2). As caraterísticas de frações granulométricas grandes e intermediárias interferem diretamente no desenvolvimento das mudas, reduzindo a densidade volumétrica, elevando a porosidade e o espaço de aeração e diminuindo a retenção de água (ZORZETO et al., 2014). Entretanto, quando se utiliza a fibra de coco no substrato, apresentam algumas vantagens, como a boa capilaridade, retenção de água e a extensa durabilidade, sem alteração das propriedades físicas (BARRETO et al., 2011).

A mudas crescidas em substratos alternativos possuíam sistema radicular mais desenvolvido (Tabela 3). Quando as mudas com raízes pouco desenvolvidas são transplantadas para o campo, apresentam dificuldade de compensar a evapotranspiração, mesmo com umidade na capacidade de campo (DURNER et al., 2002). Então, se o espaço for limitante às raízes, mais difícil será o suprimento dos fatores de produção, os tornando insatisfatório no crescimento e desenvolvimento da muda (SANTOS et al., 2012). Huang et al. (2011) relata que quanto maior a massa radicular, maior a quantidade de reservas disponíveis para crescimento no intervalo entre o transplantio e a formação de novas raízes.

Os substratos alternativos sumaúma e fibra de coco não diferiram estatisticamente quanto à massa fresca total, massa seca total e comercial e produtividade total, sendo superiores ao substrato comercial (Tabela 4).

Tabela 4. Massa fresca total (MFT), massa fresca comercial (MFC), massa seca total (MST), massa seca comercial (MSC), produtividade total (PRODT), produtividade comercial (PRODC) de almeirão cv. pão de açúcar, produzidos em diferentes substratos, Rio Branco, Acre.

\begin{tabular}{|c|c|c|c|c|c|c|}
\hline \multirow{2}{*}{ Tratamentos } & MFT & MFC & MST & MSC & PRODT & PRODC \\
\hline & & & -- (g plan & & & \\
\hline CAC & $168,96 \mathrm{bc}$ & $154,69 \mathrm{bc}$ & $14,91 \mathrm{abc}$ & $13,92 \mathrm{bc}$ & $1,88 \mathrm{ab}$ & $1,72 \mathrm{bc}$ \\
\hline Fibra de coco & 264,79 a & $243,33 \mathrm{a}$ & $24,54 \mathrm{a}$ & $22,55 \mathrm{a}$ & $2,94 \mathrm{a}$ & $2,70 \mathrm{a}$ \\
\hline Sumaúma & $198,65 \mathrm{ab}$ & $183,44 \mathrm{~b}$ & $19,14 \mathrm{ab}$ & $17,77 \mathrm{ab}$ & $2,21 \mathrm{a}$ & $2,04 \mathrm{~b}$ \\
\hline Ouricurí & $116,75 \mathrm{~cd}$ & $109,35 \mathrm{~cd}$ & $11,07 \mathrm{bc}$ & $10,27 \mathrm{~cd}$ & $1,30 \mathrm{bc}$ & $1,22 \mathrm{~cd}$ \\
\hline Golden & $80,79 \mathrm{~d}$ & $76,10 \mathrm{~d}$ & $7,22 \mathrm{c}$ & $6,36 \mathrm{~d}$ & $0,89 \mathrm{c}$ & $0,85 \mathrm{~d}$ \\
\hline $\mathrm{CV}(\%)$ & 9,54 & 16,94 & 31,63 & 6,68 & 3,57 & 16,94 \\
\hline
\end{tabular}

Médias seguidas de mesma letra não diferem $(\mathrm{p}>0,05)$ entre si pelo teste de Tukey. Casca de arroz carbonizada (CAC)

Utilizando a fibra de coco como condicionador não apresentou diferença para as variáveis analisadas (Tabela 4). A fibra de coco, também pode ser utilizada num processo de compostagem para melhorar as qualidades nutricionais antes de ser utilizada como substrato para produção de mudas (NEVES et al., 2010), por ter alta relação $\mathrm{C} / \mathrm{N}$ e baixos teores de nutrientes, principalmente fósforo (DIAS et al., 2009).

Os substratos alternativos sumaúma e casca de arroz não diferiram da fibra de coco para as variáveis massa seca total e produtividade total. A sumaúma está associado aos elevados índices de qualidade de muda, onde também proporcionou valores superiores na produção.

Por mais que o índice de qualidade de muda tenham sido inferior para casca de arroz, a muda conseguiu se desenvolver depois de transplantada, proporcionando maior produtividade total. Esses resultados também foram observados por Castoldi et al. (2014) e Simões et al. (2015) avaliando substratos alternativos, obtendo elevados índices de produtividade na cultura da alface.

O substrato comercial foi o que teve menor desempenho em todas as variáveis analisadas na fase de muda e na fase do campo (Tabela 3, 4), mesmo possuindo características físicas (Tabela 2) dentro dos padrões para substratos, como maior espaço poroso, capacidade de retenção de água e matéria orgânica, apresentou baixos valores de P e K. Os nutrientes $\mathrm{N}, \mathrm{P}, \mathrm{K}$ destacam-se por serem os mais requeridos, por suas múltiplas funções nas plantas, influenciando diretamente nos processos fotossintéticos e absorção (ALVES et al., 2008; LUZ et al., 2009). Sob deficiência desses nutrientes, ocorre a diminuição do crescimento da parte aérea, sistema radicular, aumento da produção de massa seca (BERNAL et al., 2008; DAFLON et al., 2014; GURGEL et al., 2010).

\section{CONCLUSÕES}

Os substratos contendo sumaúma e fibra de coco produzem mudas orgânicas de almeirão com maior índice de qualidade.

A produtividade no campo aumenta quando utiliza-se os substratos contendo fibra de coco, sumaúma e casca de arroz carbonizada como condicionador.

\section{REFERÊNCIAS}

ALVES, A. U.; PRADO, R. M.; GONDIM, A. R. O.; FONSECA, I. M.; CECÍLIO FILHO, A. B. Desenvolvimento 
e estado nutricional da beterraba em função da omissão de nutrientes. Horticultura Brasileira, Brasília, v. 26, n. 2, p. $292-$ 295, 2008.

ARAÚJO NETO, S. E.; AZEVEDO, J. M. A.; GALVÃO, R. O.; OLIVEIRA, E. B. L.; FERREIRA, R. L. F. Produção de muda orgânica de pimentão com diferentes substratos. Ciência Rural, Santa Maria, v. 39, n. 5, p. 1408-1413, 2009.

BARRETO, C. V.G.; TESTEZLAF, R.; SALVADOR, C. A.; 2011. Ascensão capilar de água em substratos de coco e de pinus. Bragantia, Campinas, v. 71, n. 3, p. 385-393, 2011.

BERNAL, D. A.; MORALES, L. C.; FISCHER, G.; CUEVO, J.; MAGNITSKIY, S. Caracterización de las deficiencias de macronutrientes en plantas de cebollín (Allium schoenoprasum L.). Revista Colombiana de Ciências Hortícolas, Tunja Boyaca, v. 2, n. 2, p. 192-204, 2008.

CABALlERO, R.; ORDOVÁS, J.; PAJUELO, P.; CARMONA, E.; DELGADO, A. Iron chlorosis in gerbera as related to properties of various types of compost used as growing media. Communications in Soil Science and Plant Analysis, v. 1, n. 38, p. 2357-2369, 2007.

CASTOLDI, G. FREIBERGER, M. B.; PIVETTA, L. A., PIVETTA, L. F. ECHER, M. de M. Alternative substrates in the production of lettuce seedlings and their productivity in the field. Revista Ciência Agronômica, Fortaleza, v. 45, n. 2, 2014.

COSTA, D.; DURANTE, L. G. Y.; SANTOS, A. dos; FERREIRA, C. R. Production of eggplant from seedlings produced in different environments, containers and substrates. Horticultura Brasileira, Vitória da Conquista, v. 31, n. 1, p. 139-146, 2013.

DAFLON, D. S. G.; FREITAS, M. S. M.; CARVALHO, A. J. C.; MONNERAT, P. H.; PRINS, C. L. Sintomas visuais de deficiência de macronutrientes e boro em coentro. Horticultura Brasileira, Brasília, DF, v. 32, n. 1, p. 28-34, 2014.

DELARMELINA, W. M.; CALDEIRA, M. V. W.; FARIA, J. C. T.; GONÇALVES, E. de O. Uso de lodo de esgoto e resíduos orgânicos no crescimento de mudas de Sesbania virgata (Cav.) Pers. Revista Agroambiente, Boa Vista, v. 7, n. 2, p. 184-192, 2013.

DIAS, T. J.; PEREIRA, W. E.; CAVACANTE, L. F.; RAPOSO, R. W. C.; FREIRE, J. L. O. Desenvolvimento e qualidade nutricional de mudas de mangabeiras cultivadas em substratos contendo fibra de coco e adubação fosfatada. Revista Brasileira de Fruticultura, Jaboticabal, v. 31, n. 2, p. 512-523, 2009.

DICKSON, A.; LEAF, A. L.; HOSNER, J. F. Quality appraisal of white spruce and white pine seedling stock in nurseries. Forestry Chronicle, Ontário, v. 36, n. 8, p. 1013,1960 .
DURNER, E. F.; POLING, E. B.; MAAS, J. L. Recent advances in strawberry plug transplant technology. HortTechnology, Alexandria, v. 12, n. 4, p. 545-550, 2002.

FILGUEIRA, F. A. R. Novo manual de olericultura: Agrotecnologia moderna na produção e comercialização de hortaliças. 3. ed. Viçosa: UFV, 2013. 421p.

GUIMARÃES, V. F.; ECHER, M. M.; MINAMI, K. Métodos de produção de mudas, distribuição de matéria seca e produtividade de plantas beterraba. Horticultura Brasileira, Brasília, DF, v.20, n.3, p.505-509, 2002.

GURGEL, M. T.; GHEYI, H. R.; OLIVEIRA, F. H. T. Acúmulo de matéria seca e nutrientes em meloeiro produzido sob estresse salino e doses de potássio. Revista Ciência Agronômica, Fortaleza, v.41, n.1, p.18-28, 2010.

INMET. Instituto Nacional de Meteorologia. Banco de Dados Meteorológicos para Ensino e Pesquisa. 2017. Disponível em: <http://www.inmet.gov.br/portal/ index.php?r=bdmep/bdmep>. Acesso em: 12 Jun. 2017.

HUANG, P. W.; SANTOS, B. M.; WhITAKER, V. M. Effects of cell size on the production of containerized strawberry transplants in Florida. Proceedings Florida State Horticultural Society, Lake Alfred, v.124, n.1, p.184-187, 2011.

KNAPIK, J. G.; ALMEIDA, L. S. de; FERRARI, M. P.; OLIVEIRA, E. B. de; NOGUEIRA, A. C. Crescimento inicial de Mimosa scabrella Benth., Schinus terebinthifolius Raddi e Allophylus edulis (St. Hil.) Radl. sob diferentes regimes de adubação. Boletim de Pesquisa Florestal, Colombo, PR, v.51, p.33-44, 2005.

LUENGO, R. F. A.; PARMAGNANI, R. M.; PARENTE, M. R.; LIMA, M. F. B. F. 2000. Tabela de composição nutricional das hortaliças. Brasília: EMBRAPA Hortaliças. 4p.

LUZ, J. M. Q.; ZORZAL FILHO, A.; RODRIGUES, W. L.; RODRIGUES, C. R.; QUEIROZ, A. A. Adubação de cobertura com nitrogênio, potássio e cálcio na produção comercial de cenoura. Horticultura Brasileira, Brasília, DF, v.27, n.4, p.543-548, 2009.

MOLLITOR, H. D.; FABER, A.; MARUTZKY, R.; SPRINGER, S. Peat substitute on the basis of recycled wood chipboard. Acta Horticulturae, Belgium, v.644, n.14, p.123130, 2004.

NEVES, J. M. G.; SILVA, H. P da; DUARTE, R. F. uso de substratos alternativos para produção de mudas de moringas. Revista Verde de Agroecologia e Desenvolvimento Sustentável, Mossoró, v.5, n.1, p.173-177, 2010.

PEREIRA, D. C.; GRUTZMACHER, P.; BERNARDI, F. H.; MALLMANN, L. S.; COSTA, L. A. de M.; COSTA, M. S. S. de M. Produção de mudas de almeirão e cultivo no campo, em sistema agroecológico. Revista Brasileira de Engenharia Agrícola e Ambiental, Campina Grande, v.16, n.10, p.11001106, 2012. 
SAEED, M.; BALOCH, A. R.; WANG, M.; SOOMRO, R. N.; BALOCH, A. M.; BUX, B. A.; ARIAN, M. A.; FARAZ, S. S.; ZAKRIYA, M. Use of Cichorium Intybus Leaf extract as growth promoter, hepatoprotectant and immune modulent in broilers. Journal of Animal Production Advances, v.5, n.1, p.585-591, 2015.

SANTOS, B. M., STANLEY, C. D.; WHIDDEN, A. J.; SALAME-DONOSO, T. P., WHITAKER, V. M.; HERNANDEZ-OCHOA, I. M.; HUANG, P. W.; TORRESQUEZADA, E. A. Improved sustainability through novel water management strategies for strawberry transplant establishment in Florida, United States. Agronomy, Basel, v.2, n.4, p.312-320, 2012.

SILVA, A. A.; DELATORRE, C. C. Alterações na arquitetura de raiz em resposta à disponibilidade de fósforo $\mathrm{e}$ nitrogênio. Revista de Ciências Agroveterinárias, Lages, v.8, n.2, p.152-163, 2009.

SIMÕES, A. C.; ALVES, G. K. E. B.; FERREIRA, R. L. F.; ARAÚJO NETO, S. E de. Qualidade da muda e produtividade de alface orgânica com condicionadores de substrato. Horticultura Brasileira, Brasília, DF, v.33, n.4, p.521-526, 2015.

TAIZ, L.; ZEIGER, E. Fisiologia Vegetal. 5. ed. Porto Alegre: Artmed, 2013.

TRAZZI, P. A.; CALDEIRA, M. V. W.; PASSOS, R. R.; GONÇALVES, E. O. Substratos de origem orgânica para produção de mudas de teca (Tectona grandis Linn. F.) Ciência Florestal, Santa Maria, v.23, n.3, p.401-409, 2013.

ZIETEMANN, C.; ROBERTO, S. R. Produção de mudas de goiabeira (Psidium guajava L.) em diferentes substratos. Revista Brasileira de Fruticultura, Jaboticabal, v.29, n.1, p.137-142, 2007.

ZORZETO, T. Q.; DECHEN, S. C. F.; ABREU, M. F.; FERNANDES JÚNIOR, F. Caracterização física de substratos para plantas. Bragantia, Campinas, v.73, n.3, p.300-311,2014. 